public support in a way they never were before. A century ago private subscriptions could at a pinch have supported the whole body of scientific research in Britain. To-day the man-in-the-street is the patron of science. Without his support our universities and research institutions could not pay even their salary cheques for the next quarter. Therefore the interpretation of science to the public has now become a major activity in modern society, not to be entrusted entirely to the efforts of scientific journalists ; and the British Association remains the chief instrument for this activity.

\section{HERBICIDES AND SYSTEMIC FUNGICIDES}

$\mathrm{T}$

$\mathrm{HE}$ field of herbicides and systemic fungicides is one in which planned progress depends on the collaboration of chemists and biologists. Such collaboration was exemplified by a joint meeting, held at the Imperial College, London, on March 14, of the Association of Applied Biologists and the Crop Protection Panel of the Society of Chemical Industry.

\section{Herbicides}

The morning symposium on herbicides was presided over by Mr. W. E. K. Piercy, chairman of the Crop Protection Panel. In the first paper, Dr. E. W. Simon, of King's College, London, described the assessment of the relative toxicities of phenol, $o$ - and $p$-nitrophenol and $2: 4$-dinitrophenol by five methods, including tests on fungi and higher plants. The relative toxicities of these compounds were found to be largely independent of the test organism, provided that the comparisons were made at $p \mathrm{H}$-levels at which there was little dissociation. At these levels the descending order of toxicities was : dinitrophenol, mono-nitrophenols, phenol. Lower concentrations were required in tests based on growth responses (Trichoderma and Lemna tests) than in tests in which respiration-rates of yeast and of infiltrated leaf disks of Brassica alba were measured. This finding supported the hypothesis that nitrophenols owed their toxicity to the uncoupling of oxidative phosphorylation. Relatively high concentrations were required to kill $B$. alba seedlings in spraying tests, a reflexion presumably of the high concentration gradient needed to ensure that sufficient of the compound passed through the cuticle and plant tissues to build up a toxic dose within the individual cells.

Mr. G. W. Ivens, of the Agricultural Research Council Unit of Experimental Agronomy, Oxford, speaking on the phytotoxicity of mineral oils and hydrocarbons, made the point that, while the practical use of mineral oils as herbicides had demonstrated that phytotoxicity was roughly dependent upon boiling range and aromatic content, more precise correlations between toxicity and physicochemical properties were needed before herbicidal potentialities of particular oil fractions could be predicted. Spraying results with individual hydrocarbons indicated that the order of increasing phytotoxicity was: paraffins, olefins, naphthenes, aromatics-the phytotoxicity increasing with boiling point. In such experiments, however, it was difficult to judge how the toxicity estimates were affected by differences in the penetration of liquids into the intercellular spaces of the leaves.
Such differences were eliminated by exposing detached runner-bean leaves to hydrocarbon vapours. The toxicities of representatives of all four major groups of hydrocarbons estimated in this way showed a close inverse relationship with vapour pressure, and there was little difference in toxicity between the groups. As toxicity increased, the ratios between vapour pressure of equitoxic concentrations and saturated vapour pressure (thermodynamic activity) rose, reaching 1.0 with compounds boiling at about $170^{\circ} \mathrm{C}$. Compounds of higher boiling-point were non-toxic as vapours. Leaves of a plant resistant to oil spray (parsnip) showed similar relationships; but higher concentrations were needed to cause injury and the 'activity' reached 1.0 at about $140^{\circ} \mathrm{C}$. The 'activities' of all compounds tested were between 0.3 and $1 \cdot 0$, suggesting that hydrocarbons act on plants as 'structurally non-specific' substances.

Phytotoxic effects of 'hormone' herbicides on cereal crops were described by Mr. E. B. Scragg, of the North of Scotland College of Agriculture, Aberdeen. If such herbicides were applied while the spikelet primordia were being differentiated, they induced various types of abnormalities in the ears, caused by multiplication or fusion of parts. Application of 'hormone' herbicides after the completion of differentiation of the ear could cause sterility of the florets. In all cereals, the stage of maximum susceptibility was immediately before tillering.

All the species and varieties of cereals tested were susceptible to damage. Of the herbicides in commercial use, the amine salt of $2: 4$-D $(2: 4$-dichlorophenoxyacetic acid) caused most damage and the sodium salt of $2: 4-\mathrm{D}$ least. Methoxone (sodium salt of 2-methyl-4-chlorophenoxyacetic acid) and the $n$-butyl ester of $2: 4$-D were intermediate in phytotoxicity.

The direct effect of 'hormone' herbicides upon yield was also influenced by time of application. Very early applications had in some experiments given considerable reductions in yield. In other experiments, there had been no reduction, despite the presence of a high proportion of abnormal ears. Late applications, by causing infertility of the florets, decreased yield.

Increase in grain size and in crude protein content had sometimes been found in sprayed crops. Viability of the grain did not appear to be impaired.

\section{Systemic Fungicides}

The chairman for the afternoon session, on systemic fungicides, was Mr. R. W. Marsh, president of the Association of Applied Biologists. The symposium was introduced by Prof. R. L. Wain, of Wye College, who directed attention to the modern successes in animal chemotherapy which had led to a renewed interest in the possibility of controlling plant diseases by introducing curative chemicals into the plant. This technique had been employed in the United States by Horsfall and Howard, who had obtained encouraging results, using various unrelated chemicals against systemic diseases such as the various wilts, for which other methods of control were not available.

In Britain, Crowdy and Wain, studying compounds which might be translocated in plants, found systemic fungicidal activity in certain aryloxyalkylcarboxylic acids. Brian et al. demonstrated the marked systemic fungicidal properties of griseofulvin, an antibiotic which might be present in soil. 
Many factors could influence the ability of a compound to show activity as a systemic fungicide. Thus, it might not be taken up by or transported within the plant; it might be modified chemically under the influence of plant enzymes or it might be phytotoxic. However, the biological result in any test represented the net effect of these and other factors, though any protection achieved might be entirely different if other fungi and other host plants were used.

In Nature, most plants were resistant to most pathogens. Such resistance might be related to morphological characteristics though in certain cases natural resistance could well have a chemical basis. These considerations indicated lines of approach to problems of systemic fungicidal action which might give fruitful results.

Mr. S. H. Crowdy, of Long Ashton Research Station, Bristol, distinguished between chemotherapeutants-compounds able to reduce plant disease by acting within the host-and systemic fungicides, which were chemotherapeutants readily distributed within the host and acting against a specific fungus pathogen. Usually, systemic fungicides would not prevent infection but checked the development of disease after infection had taken place. The effect of compounds was assessed on their ability to cause this check and was recorded usually by measuring the extent of disease in a stated period after infection.

Mr. Crowdy described the method of bioassay of systemic fungicides used at Long Ashton, where the chief test disease was chocolate spot of broad bean, damage to both leaves and flowers being assessed. On leaves, disease could be measured either as a visual estimate of total damage or by taking the diameters of individual lesions. The latter estimate was less liable to personal bias and less dependent on uniformity of inoculation; on the other hand, it took no account of the ability of a compound to suppress lesion formation. Flower damage was estimated as the percentage of dead flowers per inflorescence. The results obtained with this test were confused by a marked disease gradient on the host. The top leaves developed fewer lesions, and those which were formed were small. It would be possible to avoid much of this variation by omitting the top of the plant in assessment; but many of the compounds used had differential effects on organs of different age, which gave the youngest leaves a special interest.

Among the materials found successful in reducing chocolate spot in the Long Ashton tests were compounds derived from the following: benzoic acid, phenoxy-acids, naphthoxy-acids and hydroxyquinolines.

Dr. P. W. Brian, of the Butterwick Research Laboratories, Welwyn, referred to the antagonism between saprophytic micro-organisms and soil-borne plant pathogens, which might be based on the production of antibiotics by the saprophytes, many of which produced antibiotics in artificial culture. 'I'he rhizosphere would be one of the most likely loci for natural biosynthesis of antibiotics, which might then pass into plants through the roots. Experiments previously described (Nature, 167,347 ; 1951) had shown that griseofulvin, an antifungal metabolic product of the common soil mould Penicillium nigricans, would enter through the roots and thence be distributed systemically. This conferred on the plant resistance to fungal attack; control of the following diseases had been observed : Botrytis fabce on broad beans, Botrytis cinerea on lettuce, Alternaria solani on tomato, and Erysiphe graminis on oats and barley.

Dr. Brian referred to an approach to treatment of plant disease, which had received attention in the United States, namely, the systemic application of substances which might neutralize or serve as antidote to phytotoxic metabolites liberated by a plant pathogen within the host plant. Consideration of work by Gäumann and his colleagues on toxins produced by Fusarium lycopersici and by Brian and his collaborators on toxins produced by Alternaria solani suggested strongly that the toxins might vary from strain to strain of any parasitic species. The task of finding an antidote to all the possible toxins involved in any one plant disease made this approach to plant chemotherapy more complex than might be thought at first sight.

Experience at the Hawthorndale Laboratories of Imperial Chemical Industries, Ltd., in developing a standard method for evaluating the systemic activity of griseofulvin and other chemicals was briefly discussed by Dr. J. Stubbs. Alternaria solani on tomato was finally selected for this work. For root absorption tests, small tomato plants grown in sand in wax cartons were watered daily for four days with the test chemical. They were then inoculated with spore suspensions and kept at high humidity for 24 hours before being returned to the greenhouse. Disease estimation was made two days later by counting the lesions on one or more leaves of each plant. For leaf absorption tests a promising method was to spray some of the leaves while others were suitably shielded, as by a polythene envelope. This technique had not yet been fully standardized but was being developed alongside the root absorption method.

When applied by the root absorption method, griseofulvin at 0.05 per cent gave almost complete control of the disease. Other systemic fungicides gave results similar to those reported elsewhere. Persistence studies showed that griseofulvin remained fully active for four days, after which there was a fairly rapid loss of activity.

Dr. W. G. Keyworth, of the East Malling Research Station, discussed studies of the tomato Fusariumwilt tests for screening chemotherapeutants which he made at the Connecticut Agricultural Experiment Station during 1951. The test compounds were applied on ten successive days to the roots of tomato plants growing in sand. The plants were then uprooted, their roots washed and dipped in a budcell suspension of $F$. oxysporum lycopersici and the plants re-potted. A standardized assessment of wilt and vascular discoloration was made some twentyone days later, by which time the control plants were usually severely diseased. Several compounds greatly reduced disease severity.

After observations that certain of these compounds caused root injury, tests were made of other modes of root injury prior to inoculation, to determine whether this influenced subsequent wilting. The methods used were : $(a)$ dipping the roots in water at $55^{\circ} \mathrm{C}$. for thirty seconds; $(b)$ periodic pruning of the roots ; (c) treatment with compounds known to cause root injury. All three treatments greatly reduced subsequent wilting. Several compounds unlikely to be translocated in the plant (for example, hydrogen peroxide) were highly effective in reducing disease. 
Further tests showed that the effect was unlikely to be associated with fungal penetration through the injured roots but was probably caused by an induced resistance of the upper parts of the roots or of the lower stems. It was further noted that the metabolism of the injured plants had been greatly altered, inducing an accumulation of soluble carbohydrates in the aerial parts. It appeared likely that the effects of certain compounds lay in their effect on host resistance and not in systemic fungicidal action on the pathogen.

These observations emphasized the fact that the chemical treatment of plants in an attempt to obtain systemic fungicidal action might affect the host. Such effects might not necessarily be as drastic as those noted above but might, even so, play a part in any subsequent reduction in fungal invasion. The work also suggested ways in which host resistance may be further investigated.

In the lively discussion following these contributions, many speakers commented on the effect of external environmental conditions on the expression of systemic fungicidal action. These conditions presumably affected the power of the host to absorb and translocate the active compounds.

In summarizing the discussion, Prof. Wain recommended that the fundamental approach to studies on systemic fungitoxicity should not be overlooked. Such factors as the stability of compounds, their movement within the plant and the effects of systemically-acting compounds on normal plant biochemical processes should be made subjects for research. He awaited examples of control of plant diseases using systemic fungicides under field conditions.

R. W. Marsh

\section{SCIENTIFIC INSTRUMENTS FOR RESEARCH AND INDUSTRY}

\section{PHYSICAL SOCIETY'S EXHIBITION, 1952}

$\mathrm{T}$

HE thirty-sixth annual exhibition of scientific instruments, organized by the Physical Society, was formally opened by the president of the Society, Prof. L. F. Bates, on Thursday, April 3. In his opening remarks he pointed out that the Council of the Physical Society regards this exhibition as one of the most important aspects of the work of the Society. Of its national importance there can now be no doubt; after thirty-six years (excluding the war years) of steady progress it has become increasingly popular, and is now regarded as an outstanding event of 'the scientific year'. At the time of writing, the death of Sir Stafford Cripps recalls the first post-war exhibition in 1946. 'That exhibition was opened by Sir Stafford Cripps, who was then president of the Board of Trade. In his concluding remarks, after paying tribute to the excellence and importance of the scientific instrument industry, he said : "It is essential that we should have and maintain in this country a pre-eminent scientific instrument manufacture both for our own use and to help to supply those many other countries who cannot themselves afford to set up such manufactures". The Council of the Physical Society, in organizing these splendid annual exhibitions, is doing much to encourage the development of a pro-eminent scientific instrument industry. The recent thirtysixth exhibition upheld the standard set by its predecessors. It was held by kind permission of the College authorities in the large rooms of the Imperial College and of the Huxley Building, South Kensington. 'The exhibition was open for five days, from Thursday, April 3, to Tuesday, April 8 (excluding Sunday). The total turnstile figures indicated an attendance of more than 17,000 in the Main Building of the Imperial College and more than 9,000 in the Huxley Building. There can be no doubt that the extension of the exhibition to the Huxley Building has resulted in less over-crowding, and it would seem advisable now to consider a less-complicated system of issue of tickets than that hitherto found necessary.

As usual, an important feature of the exhibition were the discourses given by lecturers eminent in special branches of scientific research. On this occasion two special discourses were arranged: (1) "Engineering Supersonic Aerodynamics", by Mr. B. N. Wallis (of Vickers-Armstrong, Ltd.), and (2) "The Physical Basis of Colour Photography", by Mr. E. R. Davies (of Kodak, Ltd.). At short notice, a third discourse was given on "The Torpidity of Liquid Surfaces", by Dr. K. Hickman (of Rochester, New York).

The discourse by Mr. B. N. Wallis on "Engineering Supersonic Aerodynamics" was given on Friday evening, April 4. Mr. Wallis said that since the end of the Second World War and following the rapid development of jet propulsion, the principal interest in aerodynamics has moved from the study of fluid motion at subsonic speeds to that at supersonic speeds. In what might be called its subsonic era the anatomy of the aeroplane could be treated as substantially two-dimensional, and the problems of three-dimensional flow were of relatively minor interest. Supersonic aircraft, on the other hand, must comprise an essentially three-dimensional, as well as a two-dimensional, element in their anatomy. So great may the drag of a three-dimensional body become that three-dimensional supersonic flow is correspondingly important. Moreover, some rearrangement of the wing - body combination is necessary if an overwhelming penalty in interference drag is to be avoided. If complete freedom of anatomical arrangement be assumed, wing-body combinations can be suggested the drag of which might be less than the sum of the drags of the components taken separately. 'All-wing' and 'Delta' aircraft illustrate attempts to attain this benefit: The necessity for low drag, however, focuses attention on flow in the boundary layer. The opinion commonly held that this must be turbulent at the high Reynolds' numbers involved is based on practical rather than theoretical reasons. If the conditions known to be necessary for stable laminar flow are present, there is the possibility that it will be maintained at least over a large part of the surfaces involved. Can any anatomical arrangement be devised for the now essential association of body and wings whereby the two sets of conditions, that is, those for favourable interference drag and those for minimum frictional drag, are satisfied simultaneously ?

Mr. E. TR. Davies gave his discourse on "The Physical Basis of Colour Photography" on Monday evening, April 7. He pointed out that most colours can be matched visually by some additive mixture of a beam of red light, a beam of green light and a beam of blue light; this has long been known, and was used by Maxwell in 1861 to make the first colour photograph. All modern processes of colour photography depend on the same principle, the subtractive 